ARTICLE HISTORY: Received: September 05, 2021 Accepted: October 28, 2021 Published: November 04, 2021

УДК 541.123546.135

НОВЫЕ ИНГИБИТОРЫ КОРРОЗИИ НА ОСНОВЕ АМИНОВ И АМИДОВ

Осербаева Альфия Курбанбаевна PhD, cm.npen.

Ташкентского химико-технологи-ческого института,

Нуруллаев Шавкат Пайзиевич канд.хим.наук, профессор

Ташкентского химико-технологического института,

Рашидов Даврон Мавлон углли студент бакалавриата

Ташкентского химико-техноло-гического института,

Курбанова Раънохон Исломидин кизи

Магистрант

Ташкентского химико-техноло-гического института,

\title{
NEW CORROSION INHIBITORS BASED ON AMINES AND AMIDES
}

\author{
Oserbaeva Alfiya Kurbanbaevna \\ senior teacher PhD in Tashkent Chemical-technological institute \\ Nurullaev Shavkat Payzievich \\ candidate of chemical science, professor Tashkent Chemical \\ - Technological lnstitute, Republic of Uzbekistan \\ Rashidov Davron Mavlon o'gl \\ student of the Tashkent institute of Chemical Technology. \\ Kurbanova Ranoxon Islomidin kizi \\ master student of the Tashkent Institute of Chemistry and Technology
}

\begin{abstract}
Аннотация. В данной работе исследованы новые ингибиторы коррозии металлов в сернокислотных средах в зависимости от продолжительности процесса, концентрации ингибитора и температуры. Определены основные параметры синтеза новых ингибиторов коррозии металлов марки Ст.3 и Ст.12 с применением амин и амид содержащими органическими веществами и описаны способы получения этих ингибиторов. Изучена физико-хими-ческие свойства амин и амид содержащих органических ингибиторов корро-зии и солеотложения в кислых средах процесса.

Abstract. In this work, new inhibitors of metal corrosion in sulfuric acid media are investigated depending on the duration of the process, inhibitor concentration and temperature. The main parameters of the synthesis of new corrosion inhibitors for metals of grade St.3 and St.12 with the use of amine and amide-containing organic substances have been determined, and methods for preparing these inhibitors have been described. The physicochemical properties of amine and amide containing organic inhibitors of corrosion and salt deposition in acidic process media have been studied.

Ключевые слова: амин, амид содержащие ингибиторы, коррозия, солеотло-жения, скорость коррозии, степень ингибирования, эффективность ингиби-рования.

Key words: amine, amide-containing ingibitors, corrosion, salt deposition, corrosion rate, degree of inhibition efficiency.
\end{abstract}

Введение. Природные и другие технологические газы Шуртанского газо хи-мического комплекса (ШГХК) содержат вредные кислые примеси, таких как углекислый газ и сернистые соединения (сероводород, меркаптаны дисуль-фиды). Эти соединения вызывают коррозии труб и оборудования установок разделения природных газов. С другой стороны сернистые примеси а также их продукты сгорания загрязняют окружающую среду и оказывают вредное действие на организм человека [1-2].

На основе вышеизложенного в нашей республике в настоящее время осуществляется широкомасштабные мероприятия по синтезу и изучению физико-химических свойств новых ингибиторов коррозии металлов и солеотложения минеральных солей для химической и нефтегазовой промыш-ленности [3]. Особенно важным в этом отношение является решение этих задач для систем водоснабжения энерго- и водоемких химических произ-водств. 
Предложены многочисленные ингибиторы коррозии и отложения минеральных солей. Потребность республики к таким ингибиторам сейчас составляет более 5 тыс. тонн в год. Поэтому из-за отсутствия производства этих продуктов в Республике последние привозятся из зарубежных стран за валютные средства.

С целью разработки новых импортозамещающих и экспорториентиро-ванных ингибиторов коррозии и отложения минеральных солей на базе местного доступного сырья и вторичных материалов, нами проводились целенаправленные исследования.

Объекты и методы исследования. Материалы для исследования служили образцы в форме пластик, выполненные из стали марки Ст.3 и Ст.12. В работе использовались соли $\mathrm{Na}_{2} \mathrm{~S}_{2} \mathrm{H}_{2} \mathrm{SO}_{4}$ и $\mathrm{NaCI}$. В качестве модельной коррозионной среды использовали 5:10-3 моль/л раствор $\mathrm{H}_{2} \mathrm{SO}_{4}$ (фон), а также испытания проводились в 1-3\% ном водном растворе $\mathrm{NaCI}, \mathrm{NaOH}$ и $1-3 \%$ ном растворе $\mathrm{Na}_{2} \mathrm{~S}$. Изготовленные электроды из стали марки Ст.3 имел состав \%: $\mathrm{Fe}=98,36 ; \mathrm{C}=0.20 ; \mathrm{Mn}=0.50 ; \mathrm{Si}=0.15 ; \mathrm{P}=0.04 ; \mathrm{S}=0.05 ; \mathrm{Cr}=0.30 ; \mathrm{Ni}=0.20$; $\mathrm{Cu}=0.20 .[4]$.

Предварительная обработка образцов стали включала зачистку и поли-ровку их поверхности шлифовальной бумагой с последующим химическим обезжириванием в щелочном растворе.

Объектами исследования явились синтезированные новые амин и амид содержащие ингибиторы условно обозначенные АТКФ, ИК-1 при различных концентрациях, температурах и средах. Действие солевой среды и ингибиторов на коррозионное поведение стальных образцов (марки Ст.3, Ст.12.) определяли методами поляризационных кривых и гравиметрическим по убыли массы образца после коррозионных испытаний. Были исследованы электрохимическим методом ингибиторы и на прокорродировавшей стальной поверхности.

Поляризационные кривые стального электрода в кислых и нейтральных средах в присутствии амин и амид содержащих АТКФ и ИК-1 ингибиторов при различных концентрациях и температурах снимали на потенциостате ПИ-50.1.1, с программатором ПР-8 и потенциометром ПДА-1. При прове-дении экспериментов площадь рабочего электрода подбирали исходя из возможностей потенциостата и максимальных токов (i) в области активного растворения стали.

Результаты и обсуждение. Результаты коррозионно-электрохимического поведения электродов из стали марки Ст.3. и Ст.12 в $3 \%$ ном растворе $\mathrm{H}_{2} \mathrm{SO}_{4}$ при температуре $25^{\circ} \mathrm{C}$ и $70^{\circ} \mathrm{C}$ без добавки и с добавкой ингибиторов АТКФ и ИК-1 приведены в таблице-1, а также на рис.1.

Изменение скорости коррозии Ст.3 и Ст.12. в присутствие ингибиторов

Таблица-1.

$\left(\mathrm{C}_{\text {инг }}=0,0001 \mathrm{мг} / л\right.$, продолжительность процесса-120мг/л)

\begin{tabular}{|c|c|c|c|c|c|}
\hline нгибитор & фоH & Температура, ${ }^{\circ} \mathrm{C}$ & $\mathrm{K}_{\text {корр }} \cdot 10^{-3}$ & $Z_{s} \%$ & $\gamma, \%$ \\
\hline \multirow{4}{*}{ АТКФ } & Без ингибитора & \multirow{2}{*}{25} & 94,0 & - & - \\
\hline & С добавлением АТКФ & & 4,96 & 94,7 & 5,27 \\
\hline & Без ингибитора & \multirow{2}{*}{70} & 0,35 & - & - \\
\hline & С добавлением АТКФ & & 0,011 & 96,8 & 3,17 \\
\hline \multirow{4}{*}{ ИК-1 } & Без ингибитора & \multirow{2}{*}{25} & 5,2 & - & - \\
\hline & С добавлением ИК-1 & & 0,2 & 96,0 & 3,8 \\
\hline & Без ингибитора & \multirow{2}{*}{70} & 4,40 & - & - \\
\hline & С добавлением ИК-1 & & 0,11 & 97,5 & 3,2 \\
\hline
\end{tabular}

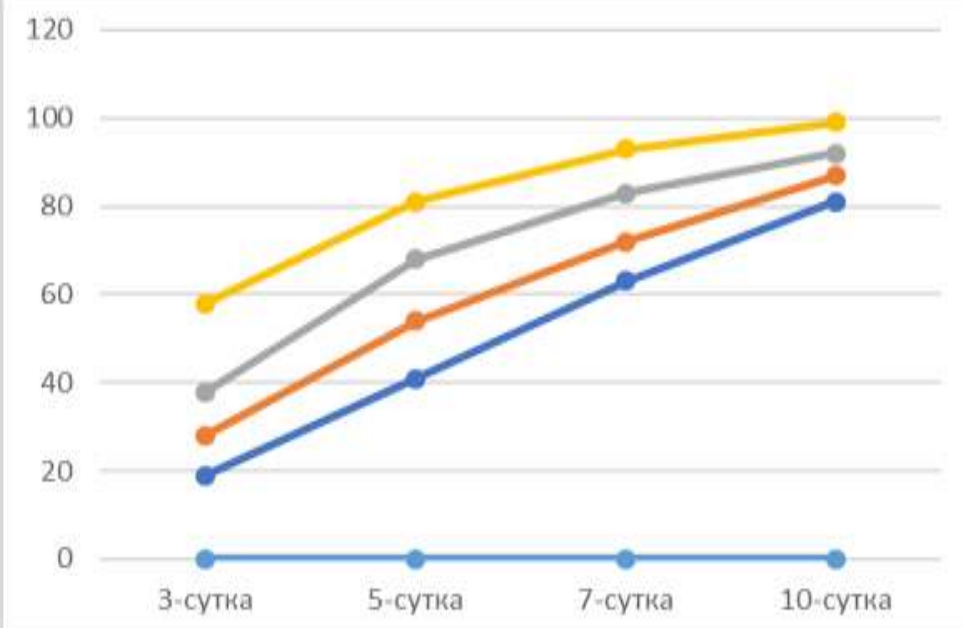


Рис.1. Зависимость степени ингибирования Ст.3 и Ст.12 в сернокислотной среде от продолжительности проиессаа при $t=25 \circ C$.

Из результатов приведенных в табл.1 и на рис.1 найдено, что ингибитор ИК-1 оказывает более эффективное влияние на степень ингибирования Ст.3 и Ст.12 в сернокислотной среде, чем ингибитор АТКФ.

С применением ингибитора ИК-1 скорость коррозии Ст.3 и Ст.12 в зависимости от концентрации ингибитора составлял $84 \div 97,5 \%$. На основе этих полученных экспериментальных данных для ингибирования процесса коррозии и солеотложения минеральных солей в оборудованиях изготовленных из сталей марки Ст.3 и Ст.12 рекомендован синтезированный новый ингибитор ИК-1.

Результаты гравиметрического определения значений скорости корро-зии (Ккор) и коэффициент торможения $(\gamma)$ при различных температурах $\left(25^{\circ} \mathrm{C}\right.$ и $\left.70^{\circ} \mathrm{C}\right)$ показывают на $7-12 \%$ чем прменяемых в настоящее время в промышленности импортных ингибиторов типа “Nalco" (Германия) и “KW -2353" (Россия). Результаты гравиметрических исследований и расчетов значений скорости коррозии и степени защиты (ингибирования) приведены на рисунках 2 и 3.

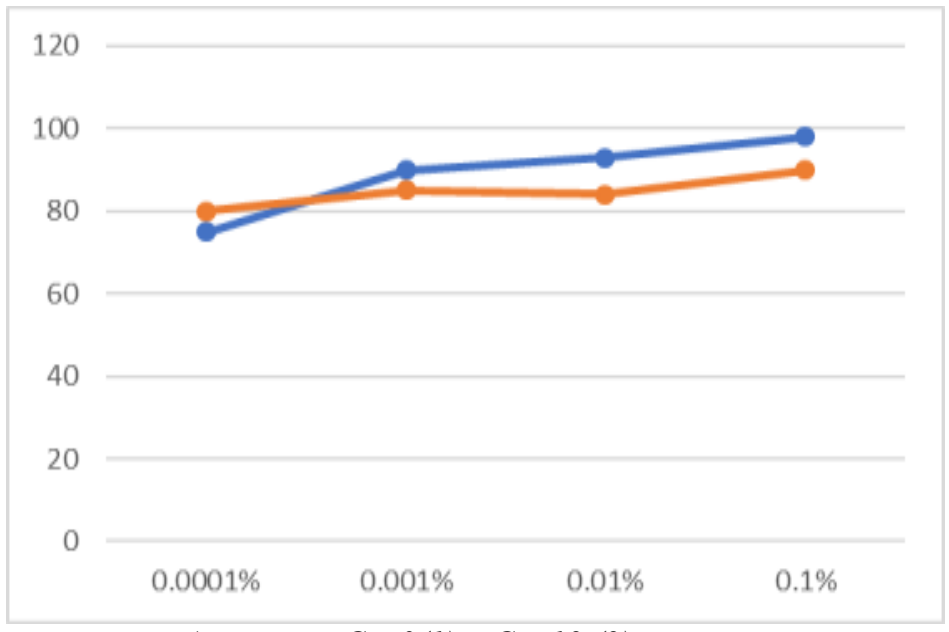

Рис.2. Зависимость степени ингибирования Ст.3(1) и Ст.12 (2) в сернокислотной среде от концентрации ингибитора $T=298 K$,

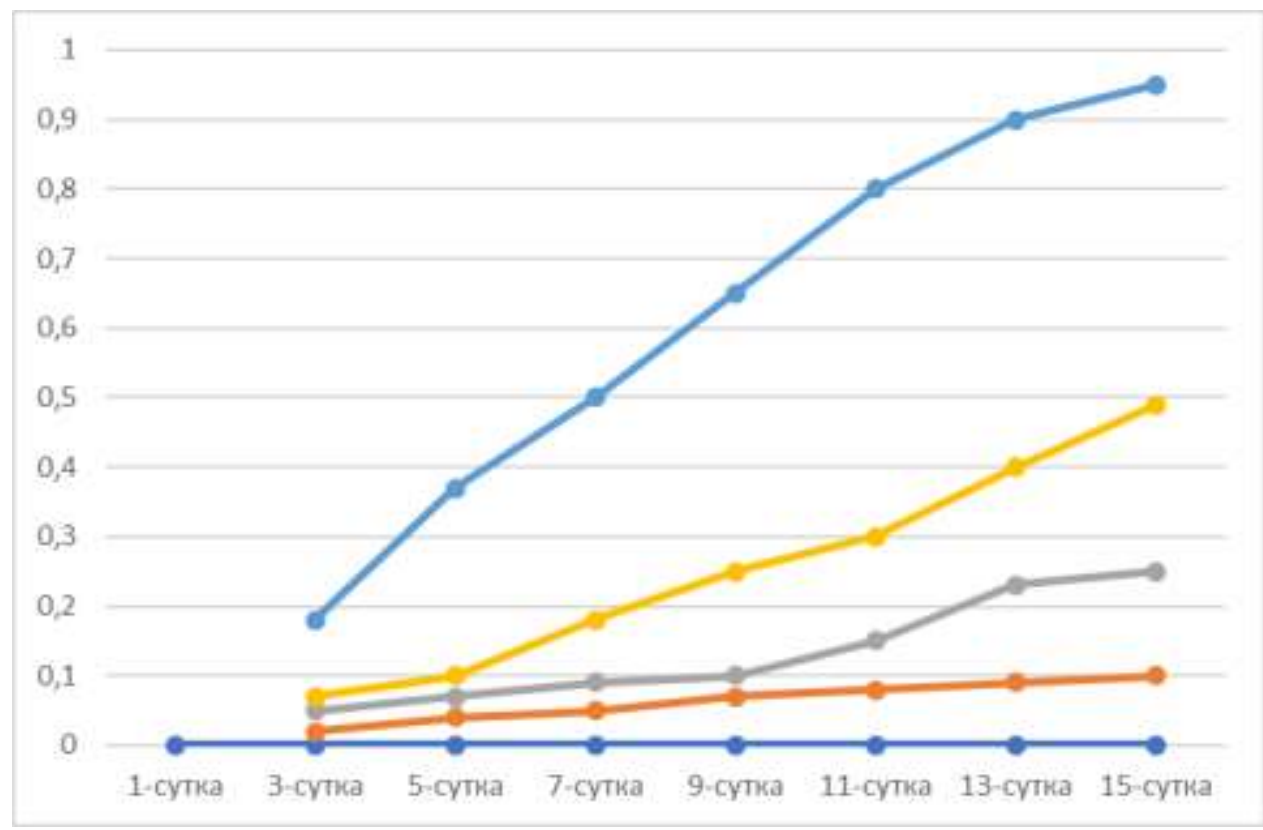

Рис.3. Зависимость скорости коррозии от продолжительности процессаа: ингибиторы АТКФ $(1,11)$ и ИК-1 $(2,21)$

Как видно из рис. 2 наиболее значительно эффективные результаты достигается в присутствии 0,0001 мг/л раствора ингибитора марки ИК-1 в сернокислых средах. Так, в зависимости от продолжительности коррозион- 
ных испытаний величина степени защитных действий ИК-1 изменяется в пределах от $75 \%$ до $89,9 \%$ (в Ст.3) и от $73 \%$ до $98,0 \%$ (в Ст.12). Характер степени защиты коррозии углеродистой стали Ст.3 в растворах $\mathrm{H}_{2} \mathrm{SO}_{4}$ и других средах примерно одинаковый. Это связано с образованием на поверх-ности замедляют диффузию кислорода к поверхности металла.

Заключение. Сопоставляя результатов проведенных исследований по коррозии сталей марки Ст. 3 и Ст.12 в растворах серной кислоты найдено высокая эффективность в присутствии ингибитора типа ИК-1. Повышение температуры процесса ингибирования до $70^{\circ} \mathrm{C}$ существенно не влияют на степени защиты металлов $75 \div 98,0 \%$.

Литература

1. Вигдорович В.И., Синютина С.Е. Универсальный ингибитор коррозии и наводораживания углеродистой стали Ст.3 в средах содержащих $\mathrm{H}_{2} \mathrm{~S}$ и $\mathrm{CO}_{2} / /$ Вестник ТГТУ, 2008, Т14. №1. -С.128-139.

2. Гафуров Р.Р., Кудрявцева И.А. Полвоняк В.К., Быстрова О.Н. Анализ защитных свойств азотфосфорсодержащих ингибиторов коррозии стали // Практика противокорр. защиты-2001, №4. -С.14-17

3. Волошин В.Ф. Исследование влияния на электродные процессы четвертичных солей 2алкилимидазолинов//Вопросы химии и химической технологии.-2003. №5.- С.105-108.

4. Осербаева А.К., Нуруллаев Ш.П. XXXIII Международная научная конфе-ренция «Техноконгресс» Кемерово 2018.С.3-7. 